passed at the termination of these studies, and are particularly strict. When a doctor of medicine wishes to graduate in surgery, he must attend one year of practical instruction, and pass a severe examination in surgery. The title of magister of ophthalmic surgery or midwifery is obtained by attending practical instruction for one session, and submitting to examinations on these special branches.

All the lectures are public, and may be attended without any fee; but there are a great many private lecturers who give instruction, and are remunerated by those who attend them. Besides the above-mentioned lectures, which must be taken out by students in medicine, there are extra courses, which are optional; they are the following:-1. History of Medicine; 2. the Use of Instruments and Surgical Apparatus; 3. Hygiène; 4. Dental Surgery; 5. Psychology. The professors, vice-director, rector, and president of the faculty, generally form the examining board, the examinations being carried on orally in Pesth and Vienna, Padua and Pavia, but in Prague they are both verbal and written. Formerly, none were admitted to these examinations except they had studied in any of the above-mentioned Austrian universities; but this system has been altered, and the students of other universities are now admitted, after having attended to a few formalities. Students from foreign countries, as Englishmen, Frenchmen, \&c., are admitted to lectures and hospital practice without any fee, and are in general treated with great kindness and civility.

Pharmacy is quite distinct from medicine and surgery, the two professions cannot be combined, and the pharmaciens must serve three years' apprenticeship, and attend for two years, Mineralogy, Zoology, Botany, Chemistry, \&c., after which they must submit to an examination.

We do not give in detail the names of the different professors of the universities just alluded to; suffice it to say, that the following are conspicuous at Vienna:-Dr. Hirtel, for Anatomy; Dr. Frnest Brizcke, for Physiology; Rosas, for Ophthalmology; Rokitansky, for Pathological Anatomy; Skoda, for Chest Complaints; Dr. Klein, for Midwifery, \&c.

There is no state examination in Austria, as instituted in Berlin; but the examination called "rifgorosum" is tantamount to it. The patroni and magistri practise somewhat like our general practitioners, except that they do not dispense medicine. In order to obtain permission to practise in Vienna, a doctor of medicine must be member of the Faculty, which title is granted after a kind of verbal examination, called "colloquium."

Military surgeons used to be educated at Vienna, in an institution founded for this purpose, called Josephinum, which, however, is now suppressed. The Josephinum was remarkable for its exquisite anatomical wax preparations. The Library and Museum of the Faculty are open to strangers, and are noted for their completeness and elegance.

\section{A NOTE ON MR. DUNN'S CASE OF HEMIPLEGIA. BY MARSHALL HALL, M.D. \\ To the Editor of The Lances.}

SIR,-Mr. Dunn's case of hemiplegia, published in your last number (p. 473), is full of interest in many respects, and in nothing more than as an illustration of the important distinction between paroxysmal and organic paralysis.

But "Dr. Todd thought the case presented a fitting opportunity of testing the nuscular irritability in hemiplegia." Now, Sir, no case could present so unfitting an opportunity of testing this question. The case is, in reality, a case of sHock -of hemiplegic shock, if you please, but still one of shock, and in such a case all who nnderstand the subject in the least know that the irritability is damaged for a time. This fac or law is the result of the simplest experiments, ten times told.

In order that Mr. Dunn's case should present a fitting opportunity for testing the irritability in hemiplegia, two things were required:

First. - Time should have been given for the subsidence of shock; and

Secondly.-Time should have been given for the manifestation of the difference of irritability in such cases.

For the greater irritability of the hemiplegic compared with the healthy limb, is a result-the result of the withdrawal of the stimulus of volition-a result which does not take place in four, or twice four days, after a violent hemiplegic shock.

After all that has been said and done, there remain two important facts:
First.-That in cases in which the influence of the cerebrum (or volition) is withdrawn for a due length of time, the paralyzed limb or limbs possess greater irritability than the unaffected limb.

Secondly.-That in the cases in which the influence of the spinal marrow is withdrawn for a due length of time, the paralyzed limb or limbs possess less irritability than the unaffected limbs.

From these facts two important conclusions immediately

The first, that the spinal marrow is the source of irritability of the inuscular fibre, (as it is also of excitability in the muscular nerve fibre.)

The second, that, as a consequence, the galvanic influence, duly applied, becomes a source of diagnosis between the cases in which the influence of the cerebrum and of the spinal maxrow is withdrawn respectively.

All this has been proved by repaated and re-repeated experiment, most carefully and cautiously made, both as to the choice of cases and the choice of instruments, in both of which Mr. Dunn's and Dr. Todd's experiments are faulty.

Without such care and caution, I am persuaded that the important physiological and practical questions before us will long remain mystified, and $I$ think the Royal Medical and Chirurgical Society did itself and the subject great justice in refusing a place in its Transactions to a case, which, however interesting in many respects, did not present a fitting opportunity of testing a question which had been brought before it three times already.

I cannot conclude this note without adverting to a most interesting case, in which $\mathrm{Mr}$. Smith and I applied the galvanic current about a year ago. It appeared to be hemiplegia, by which term I mean cerebral hemiplegia. The paralytic limb was less moved by the influence of the galvanic current than the unaffected limb. The fact, opposed to so many others, remained inexplicable, and $\mathrm{Mr}$. Smith and I constantly made it the subject of conversation. The patient came to me about a month ago. Both sides were now affected, and this not by paralysis only, but by spasm. It was a case of spinal hemiplegia!

I have recently been favoured by a paper on this subject by M. Duchenne, of Boulogne. It is a tissue of error. If I should have leisure I may send you some remarks upon it hereafter.

To revert to $\mathrm{Mr}$. Dunn's case, I must repeat that it does present an admirable illustration of the difference between paroxysmal and organic apoplexy and paralysis, on which $I$ am preparing an essay for early publication, but that it does not present a "fitting" opportunity for testing a question of vast importance in physiology and diagnosis.

I am, Sir, your obedient servant, Grosvenor-street, Oct. 26,1850 . MARshaLL HAII.

P.S.-I have just received the subjoined note from the gentleman who has witnessed all my experiments:-

Salisbury, Oct. 28,1850 .

My DeAR SIR,-I have read Mr. Dunil's case, and return you the LANCET. It appears to me that it has very little bearing on the question. The whole system seems to have been under the influence of shock, and both limbs incapable of being affected by a current of low intensity. A Cruickshank's battery of fifty plates would otherwise have produced some effect at least. We have always found a much less power sufficient.

The first experiment was performed three days after the attack, and the second, eight days. The magneto-electric machine must have been a very powerful one, and tested merely the power of the muscles. The alternating current has a different action from that produced by the ordinary galvanic battery, being one of high intensitr, whereas the latter, as used by you, is one of low intensity. Its force marks the effect produced on the irritability of the muscular fibre Had the experiment been repeated when the patient had somewhat recovered, and was in the condition detailed in the subsequent paragraph, the result would have been different.

To Dr. Marshall Hall.

Iours, very truly HeNRY SiITH.

Appontanent-Dr. R. F. Foote, a graduate of St. Andrew's, and Member of the Royal College of Surgeons, has been appointed Resident $\mathrm{M}$ redical Superintendent to Fisherton House Lunatic Asylum, Salisbury. 